\title{
Vozes do Sul: entrevista com Raewyn Connell *
}

\author{
Cynthia Hamlin" \\ Frédéric Vandenberghe $e^{* * *}$
}

Raewyn Connell ${ }^{1}$ é professora titular de sociologia na Universidade de Sydney, Austrália. Autora de mais de 20 livros e 150 artigos, sua obra inclui temas tão diversos como educação, classe, sexualidade e gênero, violência, teoria global, metodologia e até poesia. Especialmente conhecida por seu trabalho pioneiro sobre masculinidades - seu Masculinities, de 1995, foi traduzido em 13 línguas e é hoje o trabalho mais citado da área em todo o mundo as contribuições de Connell a numerosas áreas da sociologia renderam-lhe prêmios importantes, como o da Sociedade Australiana de Sociologia e da Associação Sociológica Americana.

O nomadismo temático que lhe é característico revela, entretanto, uma preocupação que confere certa unidade à sua obra: o estabelecimento de relações entre estruturas sociais de larga escala, ações coletivas e experiências pessoais. De fato, as relações entre teoria, prática e empiria são tão evidentes em seus trabalhos que, com frequência, tem-se a impressão de se estar diante de uma espécie de grounded theory. Mas é por meio de seu olhar recente sobre a teoria social, numa sociologia do conhecimento informada por aquilo que ela chama de "perspectiva do Sul global", que se pode compreender melhor sua

\footnotetext{
* Entrevista de Raewyn Connell a Cynthia Hamlin e Frédéric Vandenberghe, realizada em Caxambu-MG, em 25 de outubro de 2011. Recebida para publicação em 19 de julho de 2012, aceita em 14 de março de 2013.

** Professora de sociologia do Departamento de Ciências Sociais e do Programa de Pós-Graduação em Sociologia da UFPE. cynthiahamlin@hotmail.com

****Professor de sociologia do IESP/UERJ. frederic@iesp.uerj.br

1 Raewyn Connell é uma mulher transexual e a maior parte de sua obra foi publicada sob o nome R. W. Connell. Nesta entrevista, em acordo com suas publicações recentes, todas as referências aparecerão sob o nome Raewyn Connell.
}

cadernos pagu (40), janeiro-junho de 2013:345-358. 
ênfase nessas relações: para a autora, diferentemente do que ocorre na metrópole global, a produção do conhecimento na periferia seria menos contemplativa, mais orientada pelos movimentos sociais. Embora atribua isso, em parte, ao sistema universitário mais frágil dos países periféricos, essa característica não deve ser tomada em seu sentido puramente negativo: ao se partir de experiências comuns a países pós-coloniais da América Latina, do Sudeste da Ásia, da África e da Oceania, pode-se obter uma melhor compreensão da estrutura econômica, da situação cultural e dos problemas sociais desses países do que por meio das "teorias do norte".

Em conferência realizada no $35^{\circ}$ Encontro Anual da Anpocs (A Revolução Vindoura na Teoria Social), em 2011, Connell explorou as possibilidades do desenvolvimento de uma ciência social genuinamente global a partir de seu livro Southern Theory (2007). Como organizadores do GT de Teoria Social da Anpocs, decidimos convidá-la para desenvolver algumas das questões apresentadas em sua conferência ao final das atividades regulares do GT. Embora originalmente pensada como uma conversa informal com a autora, a estrutura de pergunta e resposta da conversa terminou permitindo sua publicação no formato apresentado aqui. Somos extremamente gratos pela oportunidade. Agradecemos ainda a Cecília E. B. Soares pela transcrição do original, em inglês, e a Sérgio Tavolaro e Renata Motta, por contribuírem com as duas últimas questões, respectivamente. A tradução do inglês é de Cynthia Hamlin.

E: A senhora é conhecida mundialmente por seu trabalho inovador sobre masculinidades, uma área que teve um papel extremamente importante na institucionalização dos chamados Estudos de Gênero. Poderia nos falar um pouco sobre sua trajetória intelectual, de como suas preocupações de ordem mais geral nas ciências sociais a levaram para o estudo das masculinidades e de como este refletiu em suas preocupações contemporâneas acerca da "Teoria do Sul"? 
RC: Tive minha iniciação nas ciências sociais como estudante, em Sidney, nos anos de 1960. Estava envolvida no movimento pacifista, nas tentativas de democratizar as universidades $e$ também no movimento dos trabalhadores. Uma das coisas que o movimento estudantil fez, em Sidney, foi o estabelecimento do que nós chamávamos de "universidade livre". Não era propriamente uma universidade - embora nós tenhamos alugado alguns prédios - mas um coletivo de aprendizagem controlado pelos estudantes. Oferecíamos cursos e programas de estudo coletivamente planejados sobre questões que acreditávamos relevantes. Criticávamos a universidade tradicional por ensinar diversos conceitos que não eram muito relevantes para o mundo no qual habitávamos. Assim, antes que isso tivesse sido feito nas universidades tradicionais, desenvolvemos um curso crítico sobre questões indígenas. Tivemos um curso, oferecido por mim, sobre atrocidades, dado o contexto da Guerra do Vietnam. Tivemos um curso sobre desigualdades de classe e de poder na Austrália. E assim por diante. O que estávamos tentando fazer era criar uma espécie de cultura intelectual em torno da expressão, que depois aprendi de um pesquisador sueco da área de trabalho, "cave onde você está" (Lindqvist, 1980). Isto é, olhe para as questões relevantes para o tempo e lugar onde você se insere e construa uma agenda intelectual a partir delas. Esse era o ethos de nossa universidade livre e acredito que isso é algo que venho tentando fazer desde então. Um dos projetos que saíram da universidade livre, e no qual trabalhei durante dez anos, consistiu na tentativa de mapear as relações de classe que estruturavam a sociedade Australiana. Terry Irving e eu escrevemos uma história da estrutura de classes na Austrália (Connell e Irving, 1980). Eu também escrevi um livro chamado Ruling Class, Ruling Culture (Connell, 1977), que atentava tanto para os padrões de poder na classe dominante australiana quanto para a cultura que a possibilitava permanecer no poder. Nessa linha, estabelecemos uma crítica ao marxismo estruturalista europeu: criticávamos Althusser, Poulantzas e toda aquela geração de teóricos porque sua versão de teoria não 
refletia a realidade australiana. Esse foi um momento do meu trabalho teórico, quando comecei minha carreira como cientista social. Isso levou a um segundo momento, por volta dos anos de 1980, suponho, quando me envolvi com pesquisas acerca das desigualdades educacionais. Fazíamos estudos com base em entrevistas, às vezes chamados de "etnografias", mas era um método ligeiramente diferente, tanto em escolas privilegiadas da elite quanto em escolas das classes trabalhadoras. Trabalhávamos naqueles tipos de questões que também estavam sendo teorizadas por Bernstein e Bourdieu, em seu trabalho inicial, na França. Mais uma vez, não estávamos satisfeitos com esses trabalhos, dado que eles não refletiam os processos que víamos diante de nós. Desenvolvemos uma crítica aos conceitos de reprodução social. Em particular, tentamos compreender a relação entre as desigualdades de classe e os processos de gênero, dado que essas conexões eram extremamente importantes. Ambas as estruturas eram importantes na vida dos jovens, dos adolescentes, nas escolas, e das famílias das quais eles vinham. Assim, estávamos tentando teorizar classe e gênero ao mesmo tempo. Isso foi antes que a linguagem sobre interseccionalidade se tornasse popular. Mas foi o ambiente, e o impacto da liberação gay, assim como da liberação das mulheres, que me levaram a tentar desenvolver uma teoria social do gênero e da sexualidade. Então, nos anos 1980 escrevi um livro chamado Gender and Power (Connell, 1987). A partir da pesquisa sobre as escolas, escrevemos um livro chamado Making the Difference (Connell et alii,1982), meu único livro traduzido para o português (e não consigo pronunciar seu título).

E: Estabelecendo a Diferença, publicado pelas Artes Médicas, em 1995.

$\mathrm{RC}$ : Foi desse contexto que meu trabalho sobre masculinidade surgiu: das lutas feministas contra o poder patriarcal, das lutas de liberação gay contra a violência e o preconceito. E, a partir da pesquisa com adolescentes, com pessoas jovens, meninos $e$ meninas, passamos a observar a construção das masculinidades e 
das feminilidades na vida real. E simplesmente não havia teorias que falassem sobre isso. Então juntamos - meio que costuramos teorias da psicanálise, da liberação gay, do feminismo, da sociologia mainstream, de onde quer que pudéssemos encontrar ideias teóricas. Nós as transformamos numa teoria estrutural do gênero e numa teoria estrutural da masculinidade que circularam internacionalmente. Esse tornou-se meu trabalho mais conhecido (Masculinities, cuja primeira edição foi de 1995). Mas na época eu não esperava isso! Apenas pensei: "certo, isso é um outro aspecto desse projeto no qual estamos envolvidos". E, ao mesmo tempo, nós estávamos fazendo um trabalho sobre sexualidade, porque esse era um momento no qual a epidemia da AIDS estava se desenvolvendo. Trabalhamos junto à comunidade gay a fim de desenvolver programas de educação popular para a prevenção da AIDS. Isso me levou, junto com meu colega Gary Dawsett, a olhar para as teorias sobre sexualidade (Connell e Dawsett, 1992). Mais uma vez, a psicanálise e Foucault, não eram muito úteis para lidarmos de forma prática com a crise da AIDS, na qual pessoas estavam morrendo. Havia se tornado urgente desenvolver uma boa teoria que pudesse realmente funcionar em mobilizações políticas práticas de prevenção. Assim - claro que nos baseamos na psicanálise, em Foucault, em tudo o que pudemos encontrar -, fundamentalmente, estávamos tentando teorizar a partir da situação e do material empírico colhido do programa de pesquisa que desenvolvemos sobre AIDS. Isso me leva aos anos de 1990 e ao projeto do que viria a se tornar Southern Theory. Eu era professora de sociologia na Austrália. No início dos anos 1990, fui para os Estados Unidos e consegui um emprego na Universidade da Califórnia, em Santa Cruz. Como pensavam que eu era uma teórica, deram-me um curso de teoria clássica para ensinar. Nos Estados Unidos, "teoria clássica" significa Marx, Weber e Durkheim, basicamente - talvez um pouco de Simmel. Eu havia passado minha carreira na Austrália mantendo esses senhores fora do currículo de sociologia porque queria que meus alunos pensassem por si mesmos, a partir de suas próprias situações e de 
suas próprias investigações. Mas lá estava eu, confrontada com a tarefa de ensinar Weber, Marx e Durkheim, e talvez um pouquinho de Simmel, para estudantes norte-americanos. Então, fiz um acordo com os estudantes: eles teriam que ler Weber, Economia e Sociedade, a coisa toda, e depois escrever um ensaio sobre Weber. Enquanto isso, eu escreveria um ensaio sobre por que eles não deveriam estar lendo Weber. E esse ensaio é, na verdade, em sua última versão, o primeiro capítulo de Southern Theory. Trata-se de uma crítica da história eurocêntrica da sociologia, do mito de origem da história da sociologia, e de um argumento acerca da importância do imperialismo na história da sociologia. Isso é absolutamente claro quando se lê textos do século XIX de pessoas como Spencer, Durkheim e muitos outros das duas primeiras gerações de pensadores sociológicos. A importância do imperialismo é muito clara. Daí, parti para uma crítica da teoria contemporânea, porque eu também tive que ensinar um curso sobre teoria contemporânea. E esse é o segundo capítulo de Southern Theory, em que faço uma crítica relativamente detalhada de Bourdieu, Giddens e (James S.) Coleman. Eu argumento como seus referenciais teóricos refletem o fato de que escrevem a partir da metrópole global, não de nossa periferia. Isso é, de fato, refletido na estrutura lógica de suas obras. Depois, efetuei uma crítica da teoria da globalização, pois a globalização era um tema muito popular na sociologia, na época. Mas todas as pessoas que escreveram sobre globalização, lidas internacionalmente, vinham da Europa e da América do Norte - e também suas explicações sobre a globalização. Elas refletem o fato de que foram escritas a partir da metrópole e não de algum outro lugar qualquer. Elas não percebem as questões sobre globalização como você as pode perceber a partir da periferia global, a partir da maior parte do mundo. Então, esse foi o início de Southern Theory. Mas, claro, esse era o caso negativo, o momento negativo da dialética. Tendo mostrado que uma sociologia eurocêntrica não era boa o bastante, tive que me perguntar: qual a alternativa? $\mathrm{O}$ que mais existe? $\mathrm{E}$ isso significou a leitura de muita literatura 
com a qual eu nunca havia me deparado. Se você ler um livro na América ou na Europa Ocidental chamado "Teoria Social" descobrirá que todas (ou quase todas) as pessoas mencionadas vêm da América do Norte ou da Europa Ocidental. Mas, na verdade, o resto do mundo é muito rico em análise social, em conceitos, em ideias teóricas. O resto do mundo vem pensando sobre colonialismo, globalização, neocolonialismo, neoliberalismo $e$ assim por diante por centenas de anos. Os intelectuais do mundo colonizado têm usado recursos riquíssimos em suas análises sociais. E esse é o restante do livro: conceitos, teorias, análises, um pouco de trabalho empírico derivados da África, da América Latina, do sul da Ásia, do Irã, da Austrália. A ideia era mostrar os recursos tremendos que já estão aí - se prestarmos atenção e começarmos a pensar que essas análises são tão dignas de respeito quanto o trabalho dos intelectuais da América do Norte e da Europa. Atualmente, estou trabalhando em um projeto sobre neoliberalismo, ideologia de mercado e políticas orientadas pelo mercado, pensados a partir do Sul global. A maioria dos textos mundialmente conhecidos sobre neoliberalismo, de pessoas como David Harvey, é escrita do norte global. Eles podem tentar falar globalmente, mas os referenciais teóricos a partir dos quais operam são aqueles criados na Europa Ocidental e na América do Norte. Naturalmente, pensam acerca da dinâmica da economia metropolitana como o cerne do neoliberalismo. É natural. Não há nada errado com isso, mas isso é muito específico. Assim, estou interessada nos entendimentos sobre as sociedades, sobre as sociedades de mercado globais, que emergem da periferia. $\mathrm{O}$ argumento de Southern Theory me força a reconsiderar muitas coisas que escrevi antes. Por exemplo - já que fiz uma teoria do norte no meu trabalho sobre gênero, 20 anos atrás - tenho que perguntar: como seria tratar do mesmo assunto agora, como uma questão da teoria do sul? E esse é exatamente o artigo que estou tentando escrever agora. Comecei esse trabalho na segunda edição do meu pequeno livro sobre gênero (Connell, 2009). Agora, estou tentando fazer isso de forma sistemática em um artigo que 
denominei Roses from the South - uma piada fraquinha, é uma valsa de Johann Strauss - ao tentar juntar o trabalho. Esses são pedaços de uma vida de trabalho. Eu afirmo que a teoria é um tipo de trabalho e deve-se prestar atenção às circunstâncias do trabalho. A teoria é, de fato, trabalho corporificado, então se deve prestar atenção ao local, à corporeidade, à experiência dos teóricos. A teoria é excitante e aberta. Nunca houve um momento mais excitante para se trabalhar com teoria do que no presente. Muitos dos velhos paradigmas dos analistas sociais parecem estar exauridos, mas a necessidade da teoria social é tremenda, justamente por causa do impacto global do neoliberalismo, da necessidade de transformações sociais e de movimentos sociais aqui e agora.

E: Em seu trabalho, a senhora efetua uma crítica muito forte ao que denomina "a virada discursiva na pesquisa sobre sexualidade" e apresenta uma grande preocupação com a dimensão material do gênero e da sexualidade em diferentes níveis: no cultural, no institucional, nos usos e adaptações do corpo, assim por diante. Como a senhora traz essa materialidade para a teoria?

$\mathrm{RC}$ : Sim, eu me preocupo muito com a virada discursiva na pesquisa sobre sexualidade e na pesquisa sobre gênero. Existe muita coisa criativa no pós-estruturalismo nessa área. Eu admiro, por exemplo, o trabalho de Judith Butler e alguns trabalhos sobre a crítica da identidade têm se mostrado muito interessantes $e$ muito frutíferos. Apesar disso, eu me preocupo. E eu suponho que me preocupo porque meu trabalho ativo sobre sexualidade começou no contexto da crise da AIDS. E, você sabe, tratar a sexualidade em sua materialidade era uma questão de vida ou morte. Se não se fizesse a coisa certa em termos de ações materiais e dos "corpos suados", como meu amigo Gary Dowsett nomeia o problema, as pessoas morreriam. Então era urgente desenvolver conceitos e estratégias que se referissem àquela dimensão da sexualidade. $\mathrm{O}$ mesmo é verdadeiro em relação à 
análise de gênero. Eu acho que existe um contraste muito interessante entre, digamos, a forma de se teorizar sobre gênero que é agora hegemônica na América do Norte, fortemente influenciada pelo pós-estruturalismo e pela teoria queer, e as formas hegemônicas de feminismo na África, onde a pobreza em massa está presente, onde existe a maior epidemia de AIDS no mundo, onde metade das pessoas são soropositivas e onde muitas dessas pessoas que morrerão de AIDS são mulheres. A transmissão heterossexual é a chave da epidemia na África. Também há uma alta taxa de mortalidade infantil e materna e essas são questões centrais de justiça social. Claro que os africanos leem o pósestruturalismo e algumas das feministas norte-americanas falam sobre maternidade, então não há uma distinção absoluta. Mas ela é bem forte. No geral, estou com os africanos: se você precisa de um ponto de partida para a análise de gênero, esse é um lugar melhor para se começar. Além disso, se você fala sobre corpos maternos, não pode evitar falar sobre homens.

E: Sua obra, aliada ao fato de que a senhora tem atuado como conselheira junto a organizações como a Unesco em questões relacionadas às desigualdades de gênero, tem tido um grande impacto na formulação de políticas públicas no mundo inteiro, inclusive no Brasil. Um de seus principais argumentos tem sido no sentido de incluir efetivamente os homens nessas políticas. Como essa inclusão pode ajudar a diminuir as desigualdades de gênero?

$\mathrm{RC}$ : De fato, não se pode falar de gênero sem se falar de homens e masculinidades. Nesse sentido, sou uma grande crítica de muitas das políticas de gênero que transformam a saúde das mulheres, a educação de meninas, e assim por diante, em um domínio político distinto da saúde dos homens e da educação de meninos. Acho que o gênero é sempre relacional. Por isso, não se pode ir muito longe em termos de políticas públicas, como aquelas relativas à violência de gênero, sem se considerar os homens, as práticas de gênero dos homens, a masculinidade e os corpos masculinos nessa relação. Claro que isso é difícil de fazer. É mais fácil na 
teoria do que na prática, dado que as políticas públicas envolvem aparatos, burocracias e constituintes. O gênero é uma área de política pública trazida à tona pelas mulheres, construída pelas feministas mediante a resistência de homens poderosos. Muitas feministas mostram-se, por isso, bastante relutantes em permitir a reentrada dos homens em uma área política que foi ganha por meio da luta contra os homens. Pode-se entender isso; no entanto, os homens são necessários. Hoje em dia existe muito ativismo por parte dos homens para a igualdade de gênero, trabalhos incríveis estão sendo desenvolvidos na África, Índia, Sudeste da Ásia a fim de trazer os homens para a luta (por exemplo, a "Rede Sonke de Justiça de Gênero" no sul da África - www.genderjustice.org.za.). Agora, deve-se admitir que, após 10 ou 15 anos, os efeitos desse tipo de trabalho ainda são muito pequenos em todos os lugares. $\mathrm{E}$ isso porque estamos nos opondo a uma estrutura social massiva. $\mathrm{O}$ gênero institucionaliza interesses, envolve divisão do trabalho, acumulação de riqueza, distribuição de renda, assim como identidades, corporificações, relações sexuais e assim por diante. Isso é difícil de ser mudado. Trata-se de uma estrutura institucionalizada absolutamente massiva - $e$ todos os cientistas sociais reconhecem a dificuldade em mudar isso. No entanto, ela muda historicamente, é produzida historicamente e mudará historicamente e por meio das lutas sociais.

E: Vista do Brasil, a Austrália não parece muito pós-colonial...

RC: Sim, e nosso governo concordaria. Nosso governo basicamente pensa que a Austrália é o $51^{\circ}$ estado dos EUA, ou talvez uma outra província britânica. Sim, você tem razão! A Austrália está mais ao Sul do que o Brasil. Eu acredito que a geografia e a terra importam. Isso é um fato curioso, mas, geologicamente, a Austrália, a África e a América do Sul estão relacionadas. Em termos de biologia evolutiva, esses continentes estão relacionados. $\mathrm{E}$ as sociedades contemporâneas dessas sociedades também estão relacionadas. Nós somos, de diversas formas, produtos do imperialismo e da colonização europeia. 
Demograficamente, a Austrália é um país feito por colonizadores. Foi colonizado pelos ingleses há cerca de 200 anos. Mas foi ocupado por uma civilização indígena por 40 ou 50 mil anos, talvez a cultura mais antiga do mundo. A tensão entre os grupos indígenas $e$ os colonizadores tem se manifestado ao longo da história moderna da Austrália e isso é um importante problema cultural e político para a geração atual. De um ponto de vista econômico, a Austrália é uma nação colonial dependente. Assim como grande parte da América Latina, nossa economia colonial era, originalmente, uma economia de exportação: nós exportávamos minerais (ouro e prata) e produtos agropecuários (particularmente trigo e lã) para a metrópole. Depois, passamos por um período de industrialização, em meados do século XX, nas linhas descritas pela CEPAL, mas sem nunca termos ouvido falar na CEPAL. Nós, também, temos passado por uma virada neoliberal, desde os anos de 1980, na qual nos desindustrializamos e retornamos a um status neocolonial como exportador de minerais (agora, principalmente carvão e ferro). Assim, nossa posição na economia global é, de fato, muito semelhante à do Brasil em termos dos problemas próprios a uma economia de tecnologia relativamente baixa e orientada para a exportação. Claro, nossa economia é menor que a do Brasil, dado que temos uma população de apenas 20 milhões de pessoas - a população de São Paulo em um continente inteiro. Nossa vida intelectual também está numa relação de dependência com a Europa e a América do Norte. Temos uma luta cultural, com muita tensão em torno da dependência cultural, o que tem sido um grande problema na vida intelectual australiana há muito tempo. Há 60 anos, um crítico literário australiano cunhou o termo "estremecimento cultural" para descrever a relação da Austrália com a Europa. Ele ainda é relevante. Assim, minha opinião é que a Austrália é uma parte rica da periferia global. Temos um padrão de vida de primeiro mundo para a população branca, mas não para a população aborígene. Nossa economia está mudando com a ascensão da China e da Índia e com a realocação global da 
produção industrial. Estamos nos tornando exportadores para essas economias, ao invés de simplesmente para a Europa. Então, esse é o ponto: uma parte rica da periferia, com todas as contradições que decorrem disso.

E: Eu reconheço o esforço da senhora no sentido de desenvolver epistemologias alternativas, no entanto, ao reafirmar a divisão centroperiferia, não correríamos o risco de romantizarmos aquilo que ocorre no Sul? Além disso, uma reificação dessa divisão não nos impediria de percebermos a periferia existente no próprio centro?

$\mathrm{RC}$ : $\mathrm{Eu}$ acho que você tem razão, existe esse risco. É um risco que eu assumo em meus próprios escritos, nos quais às vezes simplifico em excesso essa relação. E o que acabei de dizer sobre o Brasil e a Índia é parte do argumento: precisamos repensar o centro e a periferia, econômica e culturalmente. Você também tem razão ao afirmar que enfatizar a divisão centro-periferia pode nos impedir de enxergar a periferia na metrópole, a significância cultural, política e intelectual dos grupos raciais subordinados, das classes marginais e dos grupos imigrantes. Ainda assim, eu diria que existe um desequilíbrio maciço nas ciências sociais no mundo inteiro: onde buscamos nossas ideias, o que percebemos como argumentos de autoridade ou conceitos fundamentais, quem lemos! Por exemplo, até muito recentemente, Ashis Nandy, um dos intelectuais mais interessantes do mundo - um indiano famoso, intelectual público, psicólogo, crítico cultural, historiador cultural, escritor de temas como gênero e questões ambientais não estava em nenhum programa de curso nas universidades australianas. Eu poderia multiplicar esse exemplo. Recentemente, estive na África do Sul, li diversos de seus programas e o mesmo se aplica. Basicamente, seus programas de curso têm uma bibliografia europeia e norte-americana. Então, eu acho que existe uma tarefa enorme no sentido da necessidade de renovação $e$ reorganização intelectual - ao mesmo tempo em que se repensa o modelo centro-periferia e se reconhece que o capital transnacional 
na era da internet consiste em uma forma de capital distinta daquela presente na era de Marx e de Engels.

$\mathrm{E}: \mathrm{Eu}$ gostaria de questionar essa necessidade de nos reposicionarmos em termos da divisão centro-periferia, dos estudos pós-coloniais etc. Como uma pesquisadora brasileira, tenho tentado estabelecer um diálogo com autores europeus a partir de situações empíricas, mas não gostaria de estabelecer esse diálogo em termos de questões identitárias, em termos de minha localização geográfica. Como a senhora percebe esse problema?

$\mathrm{RC}$ : Eu simpatizo muito com a questão que você levantou; eu também não quero ser colocada em uma caixa identitária. Eu acho que o verdadeiro problema da crítica pós-colonial é que essa crítica foi segregada, por assim dizer, em termos de "estudos póscoloniais". Existe mesmo o risco de que uma disciplina como a sociologia passe a conter uma subdisciplina ou um comitê de pesquisa da ISA chamados "Sociologia Pós-colonial" (ver Reuter e Villa, 2010). Isso poderia se tornar uma nova especialidade, de forma que, enquanto os sociólogos pós-coloniais estudassem essa nova especialidade, tudo poderia continuar como antes. Eu realmente não gostaria que isso acontecesse. ( $\mathrm{E}$ essa não é a intenção do livro de Reuter e Villa). O que eu gostaria, o que eu espero, é que falemos com autoridade epistêmica de onde quer que falemos - o que talvez seja o que você quis dizer. Mas eu não acho que poderemos chegar num mundo em que isso seja possível sem que tenhamos reconhecido que muitos dos referenciais existentes nas ciências sociais têm suas raízes nas realidades sociais da metrópole global. Para mim, isso não é uma questão de identidade, mas de sociologia do conhecimento. A crítica pós-colonial diz respeito a uma sociologia do conhecimento das ciências sociais, conforme constituída no imperialismo, num mundo pós-imperial. E quando essa crítica for efetuada $e$ compreendida na metrópole e na maioria do mundo, então poderemos chegar a uma situação na qual todo mundo poderá falar com autoridade e ser ouvido a partir de qualquer lugar. Mas 
eu não acho que estejamos muito próximos disso, ainda. Basta olharmos para os currículos nas ciências sociais da metrópole para percebermos o quão distantes ainda estamos disso.

E: Muito obrigado.

RC: Obrigada.

\section{Referências bibliográficas}

Connell, Raewyn. Ruling Class, Ruling Culture: Studies of Conflict, Power and Hegemony in Australian Life. Cambridge, Cambridge University Press, 1977.

; IRVING, Terry. Class Structure in Australian History. Melbourne, Longman Cheshire, 1980.

; ASHENDEN, Dean; KeSSLER, S; DOWSETT, Gary. Making the Difference: Schools, Families and Social Division. Sydney, Allen \& Unwin, 1982.

. Gender and Power: Society, the Person and Sexual Politics. Sydney, Allen \& Unwin; Cambridge, Polity Press; Stanford, Stanford University Press, 1987.

; DOWSETT, Gary. (eds.) Rethinking Sex. Melbourne, Melbourne University Press, 1992.

. Masculinities. Cambridge, Polity Press; Sydney, Allen \& Unwin; Berkeley, University of California Press, 1995.

. Southern Theory: The Global Dynamics of Knowledge in Social Science. Sydney, Allen \& Unwin Australia; Cambridge, Polity Press, 2007. . Gender: In World Perspective. Cambridge and Malden, Polity Press, 2009.

LINDQVIST, Sven. Gräv där du står. Estocolmo, Bonniers, 1980.

ReUter, Julia Reuter; VILlA, Paula. (eds.) Postkoloniale Soziologie: Empirische Befunde, theoretische Anschlüsse, politische Intervention. Transcript Verlag, 2010. 